\title{
In Situ Formation of Polysulfonamide Supported Poly(ethylene glycol) Divinyl Ether Based Polymer Electrolyte toward Monolithic Sodium Ion Batteries
}

\author{
Jianjun Zhang, Huijie Wen, Liping Yue, Jingchao Chai, Jun Ma, Pu Hu, \\ Guoliang Ding, Qingfu Wang, Zhihong Liu, Guanglei Cui, * and Liquan Chen
}

\begin{abstract}
Sodium ion battery is one of the promising rechargeable batteries due to the lowcost and abundant sodium sources. In this work, a monolithic sodium ion battery based on a $\mathrm{Na}_{3} \mathrm{~V}_{2}\left(\mathrm{PO}_{4}\right)_{3}$ cathode, $\mathrm{MoS}_{2}$ layered anode, and polyether-based polymer electrolyte is reported. In addition, a new kind of polysulfonamide-supported poly(ethylene glycol) divinyl ether based polymer electrolyte is also demonstrated for monolithic sodium ion battery via in situ preparation. The resultant polymer electrolyte exhibits relatively high ionic conductivity $\left(1.2 \mathrm{mS} \mathrm{cm}^{-1}\right)$ at ambient temperature, wide electrochemical window $(4.7 \mathrm{~V})$, and favorable mechanical strength (25 MPa). Moreover, such a monolithic $\mathrm{Na}_{3} \mathrm{~V}_{2}\left(\mathrm{PO}_{4}\right)_{3} / \mathrm{MoS}_{2}$ sodium ion battery using this polymer electrolyte delivers outstanding rate capability (up to $10 \mathrm{C}$ ) and superior cyclic stability (84\%) after 1000 cycles at $0.5 \mathrm{C}$. What is more essential, such a polymer electrolyte based soft-package monolithic sodium ion cell can still power a red light emitting diode lamp and run finite times without suffering from any internal short-circuit failures, even in the case of a bended and wrinkled state. Considering these aspects, this work no doubt provides a new approach for the design of a high-performance polymer electrolyte toward monolithic sodium ion battery with exceptional rate capability and high safety.
\end{abstract}

Dr. J. J. Zhang, Dr. H. J. Wen, Dr. L. P. Yue, Dr. J. C. Chai, Dr. J. Ma, Dr. P. Hu, Dr. G. L. Ding, Dr. Q. F. Wang,

Prof. Z. H. Liu, Prof. G. L. Cui

Qingdao Industrial Energy Storage

Technology Institute

Qingdao Institute of Bioenergy and Bioprocess

Technology

Chinese Academy of Sciences

Qingdao 266101, P. R. China

E-mail: cuigl@qibebt.ac.cn

Dr. J. J. Zhang, Dr. J. C. Chai, Dr. P. Hu

University of Chinese Academy of Sciences

No. 19A Yuquan Road, Beijing 100049, China

Prof. L. Q. Chen

Beijing National Laboratory for Condensed Matter Physics Institute of Physics

Chinese Academy of Sciences

Beijing 100190, P. R. China

DOI: $10.1002 /$ smll.201601530

\section{Introduction}

At present, the extension of cost-effective battery technology for wide-scale implementation of renewable energy storage systems would be indispensable. ${ }^{[1-5]}$ Hence, sodium ion battery has received more attention as a novel and promising alternative to lithium ion battery due to the natural abundance of sodium resources and the similar intercalation chemistry of sodium and lithium. ${ }^{[6-13]}$ In general, sodium ion battery could be divided into four parts: cathode, anode, separator, and electrolyte. Currently, tremendous effort has been made to search for new positive electrode materials and negative electrode materials toward rechargeable sodium ion battery. ${ }^{[14-18]}$ Reliable and high-performance sodium ion batteries are desirable for consumer electronics, electrical vehicles, and grid energy storage. Safety issues have become a major obstacle impeding the sodium battery. Hence, besides implementation of suitable alternative electrodes, the 
investigation of electrolyte and separator is considered as a key step for developing sodium ion batteries with reliability and highly safety. Only should we balance the development between the electrode materials and separator electrolyte materials, the sodium ion battery industry could have a better future.

Generally, the most widely used separators and electrolyte for sodium ion battery were polyolefin-based separators and liquid electrolyte (such as $1 \mathrm{M} \mathrm{NaPF}_{6}$ in EC/DMC). ${ }^{\text {19-23] }}$ However, such sodium batteries using liquid electrolyte and polyolefin-based separators might exhibit severe safety risk during cycling or storage, especially at elevated temperatures, resulting from the volatilization of the electrolyte. These problems finally could deteriorate the battery performance and become a potential constraining factor for practical utility of sodium ion battery. ${ }^{[24-26]}$ One of the technologies is to develop polymer electrolyte with comprehensive performance in terms of high ionic conductivity, wide electrochemical window, and superior safety. Polymer electrolyte is undoubtedly an ideal solution due to their several advantages such as improved safety and reliability, compared to those with liquid electrolytes. Compared with polyolefin separators and liquid electrolytes, the safety and stability of batteries can be significantly improved in systems using polymer electrolyte because of their good electrochemical and thermal stability. Hence, many efforts have been made to develop advanced polymer electrolyte to boost battery performance. Kumar and Hashmi investigated ionic liquid/ $\mathrm{NaCF}_{3} \mathrm{SO}_{3}$ membranes gel polymer electrolyte toward sodium battery. ${ }^{[27]}$ Unfortunately, too high viscosity of ionic liquid was not conducive to lithium ion conduction, which was detrimental to battery performance. In addition, the ultrahigh cost and unendurable viscosity of ionic liquids would restrict the industrial application. A freestanding membrane for sodium-ion conduction in PEGMA and BEMA polymer electrolyte (doped with $\mathrm{NaClO}_{4}$ ) has been developed via a UV-induced photopolymerization solution-casting technique by Bella et al. ${ }^{[28]}$ Recently, Goodenough et al. explored a kind of low-cost glass-fiber/PVDF-HFP composite polymer electrolyte to improve battery performance. ${ }^{[29]}$ They found that such polymer electrolyte could improve battery performance to a certain degree, while the polymer electrolyte is too thick $(200 \mu \mathrm{m})$ to enhance rate capability of sodium battery. Despite these great advances, we believe that it is still challenging to make attempts especially in new design concept to improve overall performance of polymer electrolyte for sodium battery.

In the present study, we put forward a scalable and smart strategy to exploit a new class of polysulfonamide-supported poly(ethylene glycol) divinyl ether based polymer electrolyte (hereafter abbreviated as "PPDE-CPE") for monolithic sodium ion battery by facile in situ integrated preparation. To date, this is the first article to use concept of in situ polymerization for fabricating polymer electrolyte of monolithic sodium ion full battery. It was demonstrated that the obtained polymer electrolyte possessed proper mechanical strength, wide electrochemical window, improved dimensional thermostability, and superior rate capability. In addition, the soft-package monolithic sodium ion full cell can still power a red light emitting diode lamp without suffering from internal short-circuit failures even in wide-angle bending or severely wrinkled condition. There is no denying that our study opens up a new kind of perspective that it is critical for fabricating high performance polymer electrolyte toward monolithic sodium ion battery.

\section{Results and Discussion}

\subsection{In Situ Preparation of PPDE-CPE}

In situ synthesis process of PPDE-CPE was as follows: Homogeneous precursor solution was prepared by mixing $1 \mathrm{~mL}$ tri(ethylene glycol) divinyl ether (TEGDVE, Figure S1, Supporting Information), $2 \mathrm{~mL}$ organic electrolyte (1 $\mathrm{M} \mathrm{NaClO}_{4}$ in propylene carbonate) and $0.01 \mathrm{~g} \mathrm{LiBF}_{4}$ (here, $\mathrm{LiBF}_{4}$ acted as the initiator for the polymerization of TEGDVE). Subsequently, flame-retardant polysulfonamide (PSA) nonwoven was prepared via electrospinning process (Figure S2, Supporting Information). ${ }^{[30]}$ After that, homogeneous precursor solution was then poured into a PSA nonwoven and the polymerization was conducted in vacuum oven at $25^{\circ} \mathrm{C}$ for 5 h. Finally, a three dimensional framework structure filled by tri(ethylene glycol) divinyl ether based polymer electrolyte was formed in the pores of PSA nonwoven. The thickness of resultant polymer electrolyte membrane was $30 \mu \mathrm{m}$. They were stored under argon box for subsequent measurements. Compared with traditional process, such in situ preparation method greatly simplified the assembly process of sodium ion battery.

\subsection{Morphology and Physical Properties}

The typical scanning electron microscopy (SEM) images of PP separator, glass fiber, and PSA nonwoven were vividly shown in Figure 1. It can be seen in Figure 1a that the pores of PP separator are uniform and typically elliptic with the long axis of 100-300 $\mathrm{nm}$ and the short axis of about $50 \mathrm{~nm}$. The elliptic shapes of the pores are the characteristic of the uniaxially stretched microporous membrane and it may give rise to thermal shutdown or shrinkage at the elevated temperature. ${ }^{[21]}$ Meanwhile, glass fiber (Figure 1b) exhibited excessively large-sized pores between discontinuous fibers, which may lead to a decreased battery voltage due to selfdischarge phenomenon. ${ }^{[31]}$ It was observed in Figure 1c that PSA nonwoven was randomly consisted of numerous ultrafine nanofibers of $300 \mathrm{~nm}$ diameter with the pore size range of $0.5-1.5 \mu \mathrm{m}$. In addition, it also possessed tortuously labyrinth-like porous structure and with a thickness of about $30 \mu \mathrm{m}$ (Figure S3, Supporting Information).

Figure 1d shows photographs of polymer electrolyte by in situ cationic polymerization of TEGDVE. FTIR analysis was conducted to confirm in situ cationic polymerization of divinyl ethers. ${ }^{[32]}$ We found that the band at $1640 \mathrm{~cm}^{-1}(\mathrm{C}=\mathrm{C})$ corresponding to vinyl functional group of TEGDVE disappeared after the completion of polymerization (Figure S4, Supporting Information), suggesting 

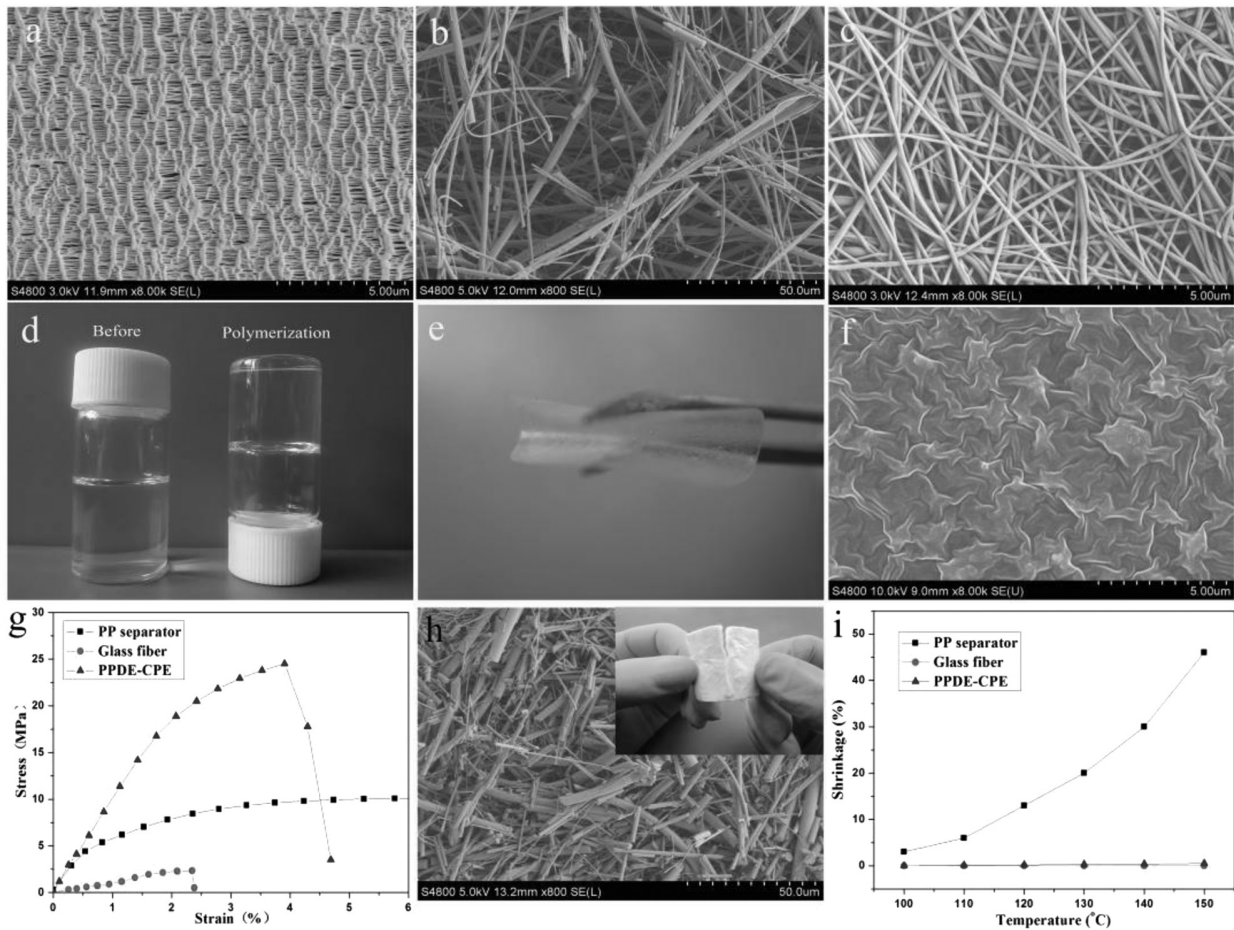

Figure 1. Typical SEM images of a) PP separator, b) glass fiber, and c) PSA nonwoven. d) Optical images of TEGDVE before and polymerization after storage at $25^{\circ} \mathrm{C}$ for $6 \mathrm{~h}$. e) Optical photograph and f) typical SEM image of PPDE-CPE. g) Optical photograph and typical SEM image of glass fiber after multiple bending. h) Thermal shrinkage ratio from 100 to $150{ }^{\circ} \mathrm{C}$ and i) stress-strain curves of PP separator, glass fiber and PPDE-CPE.

that homogeneous polymer electrolyte was obtained when the solution was stored at $25^{\circ} \mathrm{C}$ for $5 \mathrm{~h}$. An optical image of the PPDE-CPE film is presented in Figure 1e, revealing the excellent flexibility of this polymer electrolyte. In addition, typical SEM image of the PPDE-CPE film and its (Energy Dispersive Spectroscopy) EDS images are also shown in Figure 1f and Figure S5 of the Supporting Information, demonstrating the PSA-supported polymer electrolyte with continuous structure has been successfully obtained.

It is well-known that the lower mechanical performance limits the application of separator or polymer electrolyte in energy storage devices. ${ }^{[33]}$ The stress-strain curves of PP separator, glass fiber, and PPDE-CPE were shown in Figure 1g. Apparently, the mechanical strength of PPDECPE was enhanced to reach as high as $25 \mathrm{MPa}$, while the mechanical strength of PP separator and glass fiber was 10 and $2 \mathrm{MPa}$, respectively. Meanwhile, typical SEM image and digital photograph of glass fiber after repeated bended was shown in Figure 1h. Apparently, fiber structure of glass fiber after repeated bending was badly broken. Hence, in terms of actual application, PPDE-CPE could deliver more reliable mechanical stability and subsequently improve the safety of batteries. Thermal shrinkage of separators is an essential factor to evaluate battery safety characteristics. A safe separator must be qualified to prevent the electrodes from contacting each other at elevated temperatures. ${ }^{[26]}$ As shown in Figure 1i, PPDE-CPE and glass fiber exhibited negligible thermal shrinkage over a wider range of temperatures, which could address the security issues caused by the leakage of organic electrolyte. On contrast, PP separator showed a high thermal shrinkage ratio (up to $50 \%$ ) at elevated temperatures. Thus, the advisable comprehensive performances of microstructure, mechanical property, and thermal resistance of PPDE-CPE contribute to enhance the rate capability and cycling stability of sodium ion batteries. ${ }^{[30]}$

\subsection{Ionic Conductivity, Electrochemical Stability, and Interfacial Compatibility}

It is crucial to evaluate the electrochemical stability of polymer electrolyte in the operating voltage for practical battery applications. ${ }^{[34]}$ Figure 2a shows the comparison of electrochemical window of various electrolyte system. When using different liquid electrolyte $\left(1 \mathrm{M} \mathrm{NaPF}_{6}\right.$ in EC/DMC; $1 \mathrm{M} \mathrm{NaClO}_{4}$ in EC/DMC; $1 \mathrm{M} \mathrm{NaClO}_{4}$ in PC), the electrochemical window of PP separator as well as glass fiber was stable up to $4.2,4.4$, and $4.5 \mathrm{~V}$ versus $\mathrm{Na} / \mathrm{Na}^{+}$, respectively. In contrast, the anodic stability of PPDE-CPE can be further increased to $4.7 \mathrm{~V}$ versus $\mathrm{Na} / \mathrm{Na}^{+}$. This superior electrochemical stability may be attributed to the better interfacial compatibility with electrodes. ${ }^{[35,36]}$ Furthermore, we confirmed the better suitability of polyether-based polymer electrolyte (containing $1 \mathrm{~m} \mathrm{LiODFB}$ and $1 \mathrm{~m}$ PC) through testing electrochemical performance of $4.5 \mathrm{~V}$ Li-ion cells with $\mathrm{LiCoO}_{2}$ electrode (Figures S6 and S7, Supporting Information). Normal and stable charge and discharge profiles were observed in $4.5 \mathrm{~V} \mathrm{LiCoO}_{2} / \mathrm{Li}$ cell. In addition, coulombic efficiency of the cell using polyether-based polymer electrolyte was about approximately $100 \%$. Hence, polyether-based polymer electrolyte has an acceptable working voltage range for device applications including sodium batteries. 

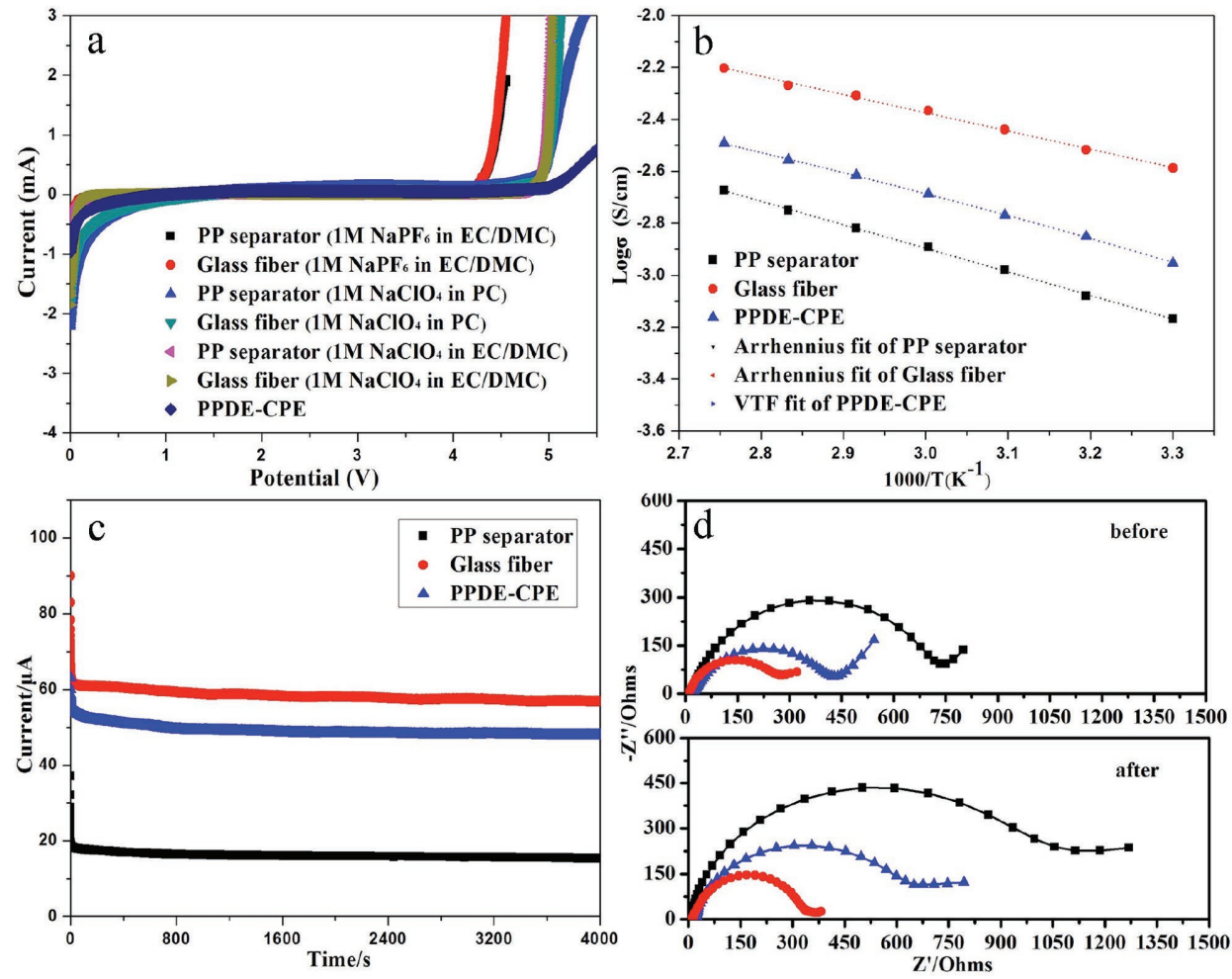

Figure 2. a) The comparison of electrochemical window of various electrolyte system. b) lonic conductivity of PP separator, glass fiber, and PPDE-CPE as a function of temperature. c) Time-current curves following a direct current (DC) polarization of $10 \mathrm{mV}$ for PP separator, glass fiber, and PPDE-CPE. d) Their Nyquist profiles of the cell electrochemical impedance spectroscopy response before and after DC polarization.

Ionic conductivity is considered to be another key factor of electrolyte for its practical application. As is known, there are two behavior of ionic conductivity for electrolyte. The first is the Arrhenius equation. Another is described by the Vogel-Tamman-Fulcher (VTF) empirical equation

$\sigma=A \exp \left(-E_{\mathrm{a}} / R T\right)$

$\sigma=A T^{-1 / 2} \exp \left[-E_{\mathrm{a}} / R\left(T-T_{0}\right)\right]$

where $\sigma$ is ionic conductivity, $E_{\mathrm{a}}$ is the activation energy related to the segmental mobolity, $A$ is the pre-exponential factor that depends on the material propert related to the charge carrier density, $R$ is the ideal gas constant, $T_{0}$ is the equilibrium glass transition temperature usually found to be $30-50{ }^{\circ} \mathrm{C}$. Figure $2 \mathrm{~b}$ illustrated the relationship between $\log \sigma$ and $1000 / T$. It can be clearly seen that the $\log \sigma$ versus $1000 / T$ for PP separator and glass fiber can be well fitted by linear relationships, indicating the temperature dependence of ionic conductivity for these two samples can be well modeled by Arrhenius equation. In comparison, a nonlinear best-fit is used to describe PPDE-CPE by VTF equation. In addition, the corresponding values of ionic conductivity, $E_{\mathrm{a}}$ and $\mathrm{t}_{\mathrm{Na}+}$ for three samples are also listed in Table 1. It is worth noticing that the $E_{\text {a }}$ value of PPDE-CPE $\left(6.4 \mathrm{KJ} \mathrm{mol}^{-1}\right)$ is little lower than that for liquid electrolyte with PP separator $\left(7.6 \mathrm{KJ} \mathrm{mol}^{-1}\right)$, demonstrating that the movement of ions in PPDE-CPE needs a relatively lower energy as that in liquid electrolyte with PP separator. As shown in Figure S8 of the Supporting Information and Table 1, the ionic conductivity of PP separator, glass fiber and PPDE-SPE of 0.36, 2.6, and $1.2 \mathrm{mS} \mathrm{cm}{ }^{-1}$, respectively. The ionic conductivity of PPDE$\mathrm{CPE}$ is lower than that of glass fiber. However, taking into account other factors, such as mechanical property, electrochemical stability, PPDE-CPE would be more beneficial to the performance of the cells.

In general, both the cationic and anionic motion contributes significantly to the total ionic transport in the polymer electrolytes. Hence, cationic transport number measurement is a key parameter to evaluate the performance of the electrolytes from their application point of view in rechargeable batteries. In the present case, the transport number $\left(\mathrm{t}_{\mathrm{Na}_{+}}\right)$of sodium ions in the liquid electrolyte-soaked polymer electrolyte is obtained from a combination of AC impedance and DC polarization techniques. ${ }^{[37]}$ In this technique, the Na/polymer electrolyte/ $\mathrm{Na}$ cell was polarized at constant potential by applying a voltage, $\Delta V=10 \mathrm{mV}$ and the resultant current

Table 1. The values of ionic conductivity, $E_{\mathrm{a}}$ and $\mathrm{t}_{\mathrm{Na}+}$ of PP separator, glass fiber, and PPDE-CPE at $25^{\circ} \mathrm{C}$.

\begin{tabular}{lccc}
\hline Samples & $\begin{array}{c}\text { Ionic conductivity } \\
{\left[\mathrm{S} \mathrm{cm}^{-1}\right]}\end{array}$ & $\begin{array}{c}E_{\mathrm{a}} \\
{\left[\mathrm{KJ} \mathrm{mol}^{-1}\right]}\end{array}$ & $\mathrm{t}_{\mathrm{Na}+}$ \\
\hline PP separator & 0.36 & 7.6 & 0.25 \\
Glass fiber & 2.6 & 5.5 & 0.29 \\
PPDE-CPE & 1.2 & 6.4 & 0.46 \\
\hline
\end{tabular}


were monitored as a function of time. As shown in Figure 2c,d and Table 1, the cationic transport number of liquid electrolyte-soaked PP separator, glass fiber and PPDE-CPE were $0.25,0.29$, and 0.46 , respectively. It is obvious that $t_{\mathrm{Na}+}$ for polymer electrolyte based on TEGDVE is much higher than that of PP separator and glass fiber. The reason could be ascribed to the polarity of TEGDVE, which restrains the movement of large $\mathrm{ClO}_{4}^{-}$anions. High $\mathrm{Na}^{+}$transference number of PPDE-SPE will be of significance to reduce the polarization during battery charging/discharging process. ${ }^{[38]}$

\subsection{Electrochemical Performance Evaluation of $\mathrm{Na}_{3} \mathrm{~V}_{2}\left(\mathrm{PO}_{4}\right)_{3} /$ $\mathrm{Na} \mathrm{Half}$ Cell and $\mathrm{MoS}_{2} / \mathrm{Na}$ Half Battery at $25^{\circ} \mathrm{C}$}

The SEM image, shown in Figure 3a, reveals that the asprepared $\mathrm{Na}_{3} \mathrm{~V}_{2}\left(\mathrm{PO}_{4}\right)_{3}$ consists of agglomerates of primary particles having a size of about $40-60 \mathrm{~nm}$. Figure $3 \mathrm{~b}$ presents the X-ray diffraction (XRD) patterns of the resultant
$\mathrm{Na}_{3} \mathrm{~V}_{2}\left(\mathrm{PO}_{4}\right)_{3}$ sample. All of the diffraction peaks are indexed to the R-3c space group and in good agreement with that reported in the literature. ${ }^{[39]}$ We further examined the rate capability of the $\mathrm{Na}_{3} \mathrm{~V}_{2}\left(\mathrm{PO}_{4}\right)_{3} / \mathrm{Na}$ cells using PP separator, glass fiber and PPDE-CPE. As shown in Figure 3c, the specific discharge capacities of the $\mathrm{Na}_{3} \mathrm{~V}_{2}\left(\mathrm{PO}_{4}\right)_{3} / \mathrm{Na}$ cell using PPDE-CPE were 100.7, 100, 99.2, 98, 95.8, 93.7, 86.6, 78.8, and $67.5 \mathrm{mAh} \mathrm{g}^{-1}$ correspondingly at varied rates of $0.2,0.5,1,2$, $3,4,6,8$, and $10 \mathrm{C}$, which were much better than those of PP separator. Inferior rate capability of PP separator can be attributed to its lyophobic characteristics and poor wettability with carbonate electrolyte. In comparison with glass fiber, discharge capacities of the cell using PPDE-CPE were similar to that of glass fiber at low rates $(0.2,0.5,1,2 \mathrm{C})$. However, when at relatively high rate $(3,4,6,8$, and $10 \mathrm{C})$, rate performance of PPDE-CPE based battery was worse than that of battery using glass fiber. The difference in rate capability could be ascribed to the ionic conductivity from the different
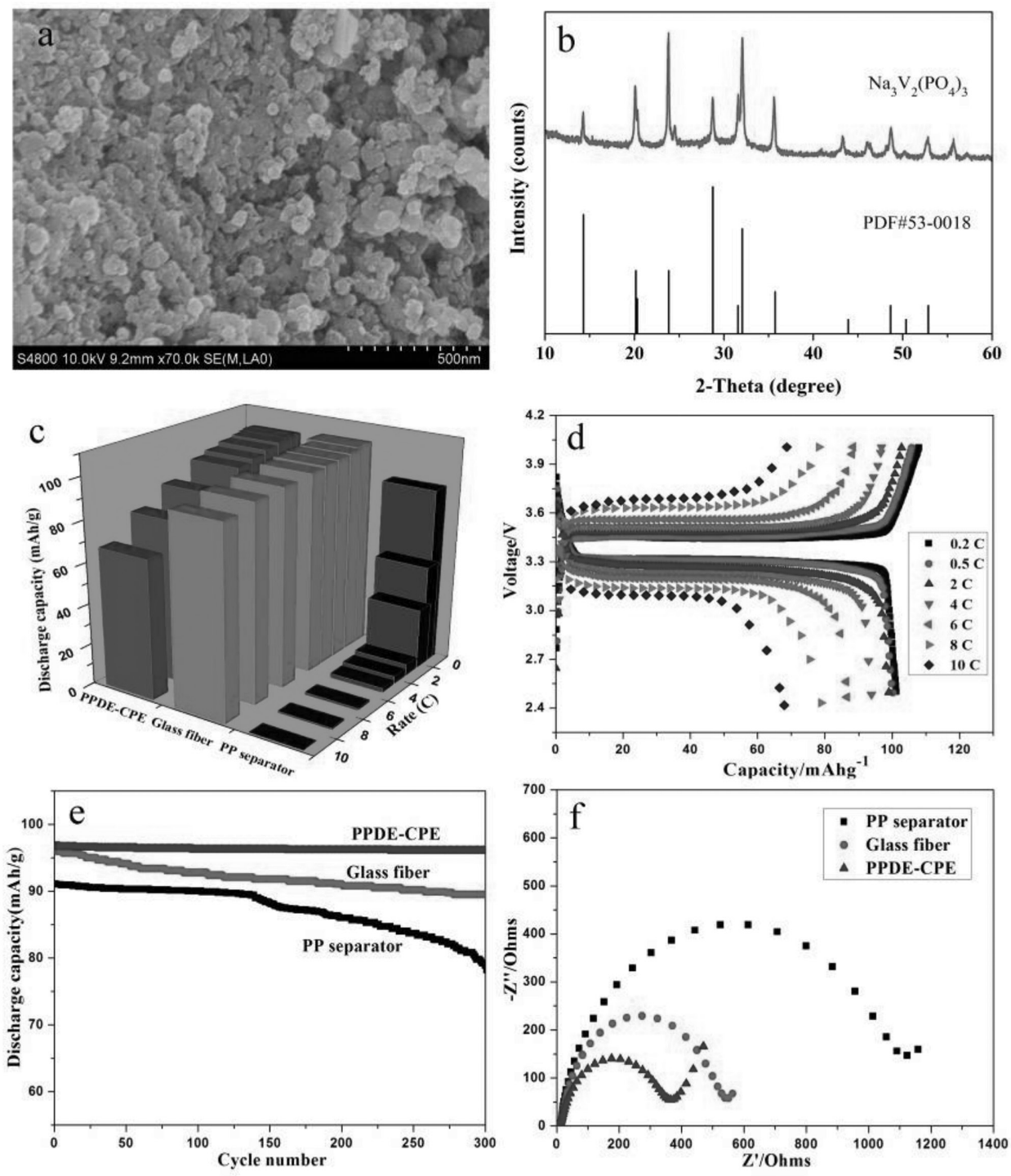

Figure 3. a) Typical SEM image and b) XRD pattern of $\mathrm{Na}_{3} \mathrm{~V}_{2}\left(\mathrm{PO}_{4}\right)_{3}$ sample. c) Rate capability of $\mathrm{Na}_{3} \mathrm{~V}_{2}\left(\mathrm{PO}_{4}\right)_{3} / \mathrm{Na}$ half cells using PP separator, glass fiber and PPDE-CPE, respectively. d) The charge/discharge profiles of $\mathrm{Na}_{3} \mathrm{~V}_{2}\left(\mathrm{PO}_{4}\right)_{3} / \mathrm{Na}$ half cell using PPDE-CPE at varied current rates. e) Cycle performance of $\mathrm{Na}_{3} \mathrm{~V}_{2}\left(\mathrm{PO}_{4}\right)_{3} / \mathrm{Na}$ half cells using PP separator, glass fiber, and PPDE-CPE, respectively. $\mathrm{f}$ ) Impedance spectrum for the half cell using PP separator, glass fiber, and PPDE-CPE after 300 cycles. 
electrolyte. ${ }^{[27-29]}$ In addition, to further investigate the relationship between power density and energy density of polymer $\mathrm{Na}_{3} \mathrm{~V}_{2}\left(\mathrm{PO}_{4}\right)_{3} / \mathrm{Na}$ batteries quantitatively, we detected Ragone plot (Figure S9, Supporting Information) of polymer sodium battery using PPDE-CPE. It was interesting that the polymer sodium cells employing such polymer electrolyte can still deliver excellent rate capability and relatively high energy density at $20{ }^{\circ} \mathrm{C}$, further proving its practicability and reliability using PPDE-CPE. As mentioned above, the thickness of glass fiber was $200 \mu \mathrm{m}$, which is too thick to promote overall performance of the battery. Taking into account other critical factors, such as physical property, electrochemical and interfacial stability, PPDE-CPE would be more beneficial to the performance of the cells.

Figure $3 \mathrm{e}$ showed cycle performances of half cells using PP separator, glass fiber and PPDE-SPE up to 300 cycle number, where glass fiber and PPDE-CPE was set at $3 \mathrm{C}$, PP separator was set at $0.2 \mathrm{C}$ due to its low discharged specific capacity at $3 \mathrm{C}$. After 300 cycles, the discharged capacity retention of PPDE-CPE was 97.7\% without distinct losses, which was much higher than that of glass fiber $(92.9 \%)$ and PP separator $(80 \%)$. In order to test self-discharge phenomenon, the ability of voltage retention, we detect the vibration of open-circuit voltage of the batteries after fully charged using glass fiber and PPDE-CPE. As can be seen from Figure S10 of the Supporting Information, the opencircuit voltage of glass fiber and PPDE-CPE were finally leveling out at around $3.39 \mathrm{~V}$. Although glass fiber based cells had an excellent rate performance and cycle performance, the open-circuit voltage of this kind of cells would reduce sharply after $25 \mathrm{~h}$ when they were at idle state, which could be attributed to self discharge phenomenon. By comparison, PPDE-CPE had a better voltage retention performance for a long time storage.

To achieve more comprehensive understanding for better cycling performance of the half cells, the interfacial resistance after the 300th cycle process was tracked in Figure 3f. The bulk resistance of impedance spectrum is obtained from the intercept on the real-axis at high frequency, and the interfacial resistance calculated from the difference between the intercept at low frequency and bulk resistance, that is the semicircle in the impedance spectrum represents the interfacial resistance. ${ }^{[23,24]}$ The interfacial resistance of the cells containing PPDE-CPE was $400 \Omega$ after 300 cycles. While the cells containing glass fiber and PP separator were 550 and $1100 \Omega$, respectively. This result was consistent with the cycle performances of half cells using different separators or polymer electrolyte. ${ }^{[31]}$

The morphology of $\mathrm{MoS}_{2}$ was observed by SEM imaging, as shown in Figure 4a. The crystal structure of $\mathrm{MoS}_{2}$ was characterized using XRD as shown in Figure $4 \mathrm{~b}$. The diffraction profiles demonstrate the phase purity of $\mathrm{MoS}_{2}$ with crystallized hexagonal structure (JCPDS 65-0160). ${ }^{[40]}$ As shown in Figure $4 \mathrm{c}, \mathrm{MoS}_{2} / \mathrm{Na}$ cell using PPDE-CPE also exhibits good high rate capability. Even at a high current density of $10 \mathrm{C}$ (discharge/charge time: $<6 \mathrm{~min}$ ), discharge capacity was as high as $90 \mathrm{mAh} \mathrm{g}^{-1}$. High reversible capacities of $155 \mathrm{mAh} \mathrm{g}^{-1}$ at $0.2 \mathrm{C}, 150 \mathrm{mAh} \mathrm{g}^{-1}$ at $0.5 \mathrm{C}, 140 \mathrm{mAh} \mathrm{g}^{-1}$ at $1 \mathrm{C}, 135 \mathrm{mAh} \mathrm{g}^{-1}$ at $2 \mathrm{C}, 130 \mathrm{mAh} \mathrm{g}^{-1}$ at $3 \mathrm{C}, 125 \mathrm{mAh} \mathrm{g}^{-1}$ at $4 \mathrm{C}, 118 \mathrm{mAh} \mathrm{g}^{-1}$ at $6 \mathrm{C}, 110 \mathrm{mAh} \mathrm{g}^{-1}$ at $8 \mathrm{C}$, and $90 \mathrm{mAh} \mathrm{g}^{-1}$ at $10 \mathrm{C}$ could be achieved, demonstrating outstanding high-rate performances of $\mathrm{MoS}_{2} / \mathrm{Na}$ cell using PPDE-SPE. Continuous
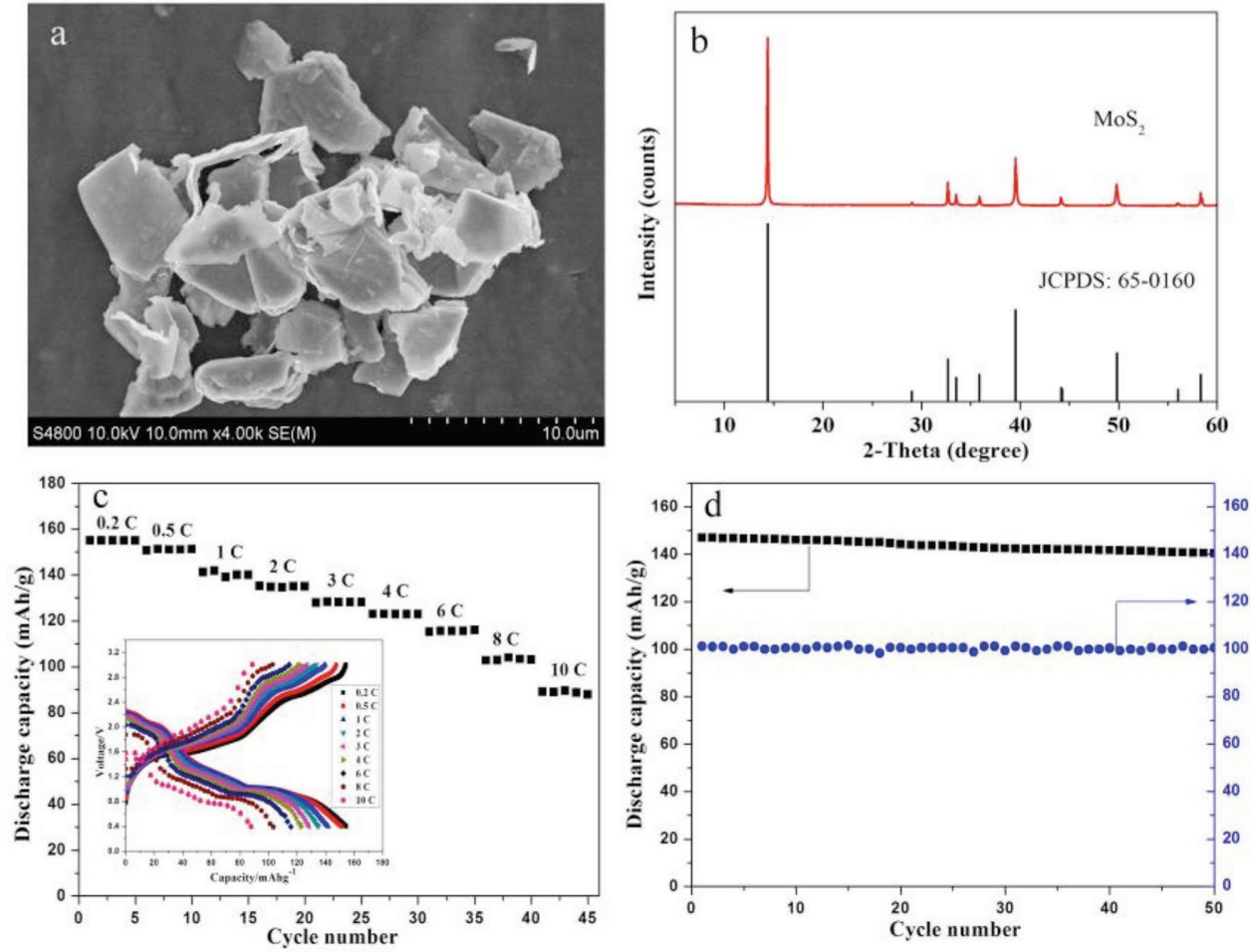

Figure 4. a) Typical SEM image and b) XRD pattern of $\mathrm{MoS}_{2}$ sample, c) rate capability of $\mathrm{MoS}_{2} / \mathrm{Na}$ cell at rates varying from 0.2 to $10 \mathrm{C}$ at room temperature. The inset is charge/discharge profiles. d) Its cycle performance and coulomb efficiency at $0.5 \mathrm{C} .\left(1 \mathrm{C}=117 \mathrm{~mA} \mathrm{~g}^{-1}\right.$.) 

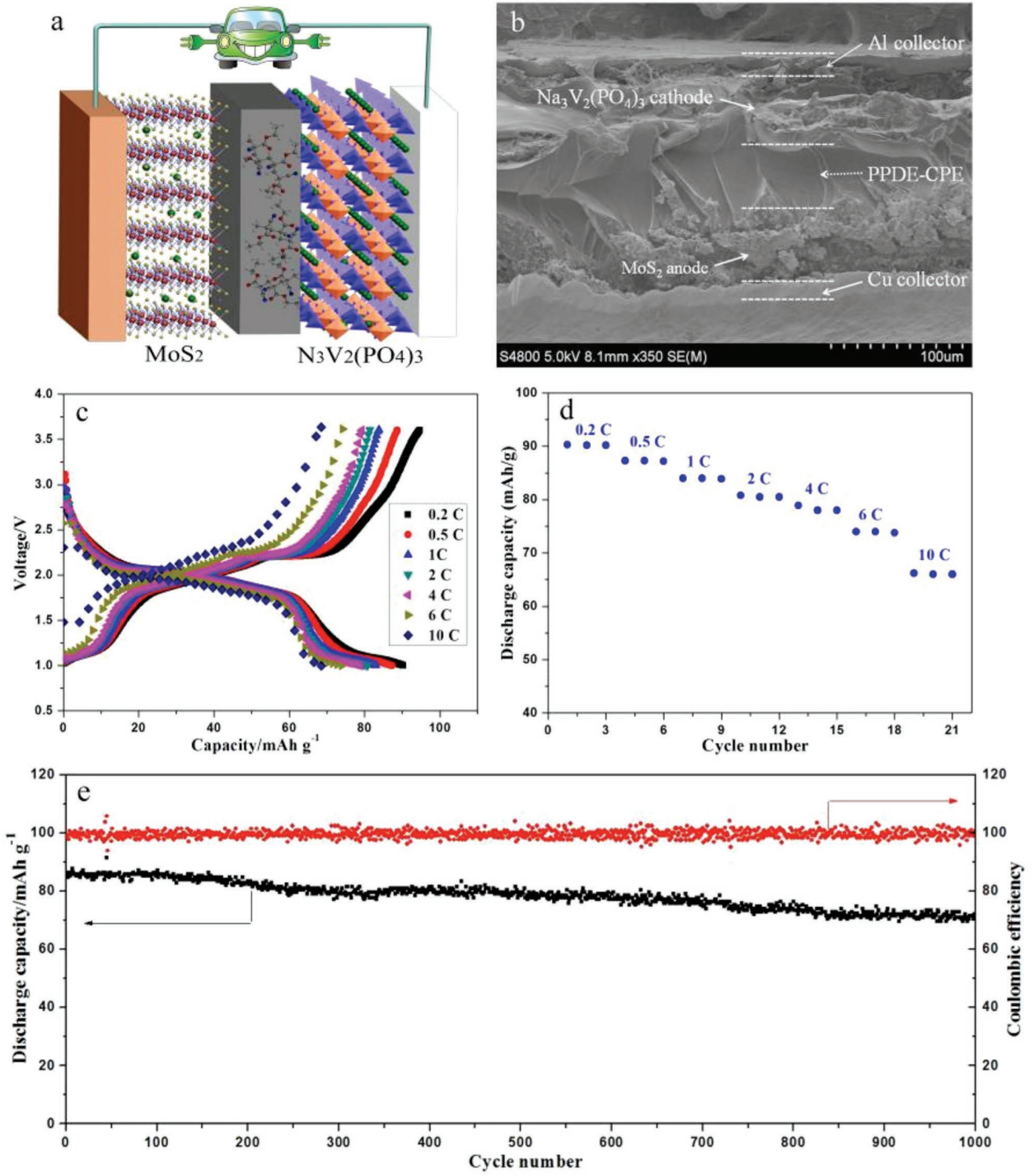

Figure 5. Flexible $\mathrm{Na}_{3} \mathrm{~V}_{2}\left(\mathrm{PO}_{4}\right)_{3} / \mathrm{MoS}_{2}$ monolithic sodium-ion full cell. a) Schematic illustration for the fabrication of the monolithic sodium-ion full cell. b) Typical cross-section SEM image of monolithic sodium-ion full cell. c) Rate capability and d) charge/discharge profiles of $\mathrm{Na}_{3} \mathrm{~V}_{2}\left(\mathrm{PO}_{4}\right)_{3} /$ $\mathrm{MoS}_{2}$ sodium-ion full battery at varied rates over the potential range of 1-3.6 V. e) Long-term cycling performance and its corresponding coulombic efficiency of the sodium-ion full cell at $0.5 \mathrm{C}$.

cycling of $\mathrm{MoS}_{2} / \mathrm{Na}$ cell using PPDE-CPE for 50 cycles was carried out at $0.5 \mathrm{C}$ (Figure $4 \mathrm{~d}$ ), The stable capacity delivery of nearly $100 \%$ coulombic efficiency, indicated the excellent cycling stability of $\mathrm{MoS}_{2} / \mathrm{Na}$ cell using PPDE-CPE.

\subsection{Battery Performance and Safety Evaluation of $\mathrm{Na}_{3} \mathrm{~V}_{2}\left(\mathrm{PO}_{4}\right)_{3} / \mathrm{MoS}_{2}$ Monolithic Sodium-Ion Full Battery}

To validate the practical feasibility of $\mathrm{Na}_{3} \mathrm{~V}_{2}\left(\mathrm{PO}_{4}\right)_{3}$ and $\mathrm{MoS}_{2}$ in a sodium metal free battery, monolithic $\mathrm{Na}_{3} \mathrm{~V}_{2}\left(\mathrm{PO}_{4}\right)_{3} / \mathrm{MoS}_{2}$ sodium ion full cells were assembled (Figure 5a) and measured between 1 and $3.6 \mathrm{~V}$ at the varied rates (Figure 5b,c). PPDE-CPE based sodium ion full battery exhibited specific capacities of $91 \mathrm{mAh} \mathrm{g}^{-1}$ at $0.2 \mathrm{C}, 88 \mathrm{mAh} \mathrm{g}^{-1}$ at $0.5 \mathrm{C}$, $83 \mathrm{mAh} \mathrm{g}^{-1}$ at $1 \mathrm{C}, 81 \mathrm{mAh} \mathrm{g}^{-1}$ at $2 \mathrm{C}, 79 \mathrm{mAh} \mathrm{g}^{-1}$ at $4 \mathrm{C}$, $74 \mathrm{mAh} \mathrm{g}^{-1}$ at $6 \mathrm{C}$, and $70 \mathrm{mAh} \mathrm{g}^{-1}$ at $10 \mathrm{C}$, respectively. In addition, sodium ion full battery delivers a reversible capacity of $87 \mathrm{mAh} \mathrm{g}^{-1}$ at $0.5 \mathrm{C}$ and high capacity retention of $84 \%$ after 1000 cycles (Figure 5d), indicating the excellent cyclability of $\mathrm{Na}_{3} \mathrm{~V}_{2}(\mathrm{PO} 4)_{3} / \mathrm{MoS}_{2}$ sodium-ion full cell employing such polymer electrolyte.

Safety performance and flexibility of soft package battery is significant for the application of large-size battery. However, recently many accidents including thermal runaway and explosion result from the existence of thermally shrinkable separator and combustible organic gases. ${ }^{[30]}$ So the electrolyte system should exhibits very good safety characteristic including better thermal stability. As above-mentioned glass fiber was unable to realize the coiling process because of the poor mechanical strength. While the flexible PPDE-SPE was suitable for the soft packaged battery are assembled by coiling process, avoiding short-circuit, and thermal runaway. 

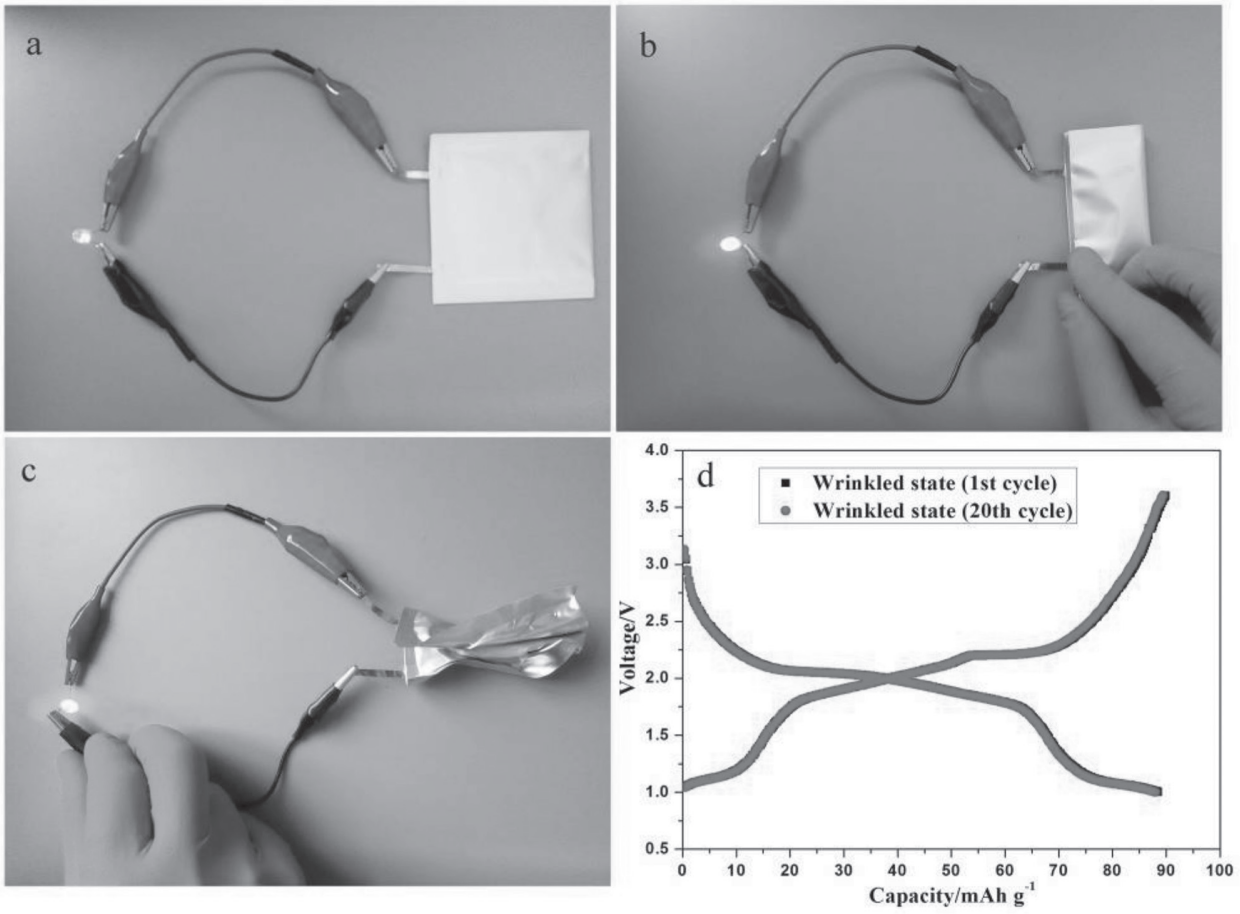

Figure 6. Optical photographs for the soft package $\mathrm{Na}_{3} \mathrm{~V}_{2}\left(\mathrm{PO}_{4}\right)_{3} / \mathrm{MoS}_{2}$ sodium-ion full cell with PPDE-CPE that powers a red LED: a) Free-bending, b) bending, and c) wrinkled. d) Charge/discharge curves of the wrinkled $\mathrm{Na}_{3} \mathrm{~V}_{2}\left(\mathrm{PO}_{4}\right)_{3} / \mathrm{MoS}_{2}$ soft package sodium-ion full cell after the first and the 20 cycle test (charge/discharge current density $=0.5 / 0.5 \mathrm{C}$ ).

Finally, in order to explore the reliability of PPDE-SPE to flexible sodium-ion full cell with shape versatility, soft package cells comprising $\mathrm{Na}_{3} \mathrm{~V}_{2}\left(\mathrm{PO}_{4}\right)_{3}$ (as cathode), $\mathrm{MoS}_{2}$ (as anode), and PPDE-CPE were developed and their performance was evaluated as a function of mechanical deformation. To demonstrate its potential application, the asfabricated flexible full cell was used to power a commercial red light-emitting diode (LED). Figure 6a shows that, under a free-bending condition, the cell is successfully able to light up a red LED lamp. As demonstrated in Figure $6 b$ and Video S1 of the Supporting Information, a LED can also be powered even when the battery was bended. No electrical failure was observed during the process of battery. Figure $6 \mathrm{c}$ displayed that the red LED lamp is still running even after the cell is severely wrinkled. We also provided charge/discharge profiles of the cell under this harsh condition (Figure 6d). It is worth mentioning that PPDE-CPE based sodium ion battery can still charge and discharge for finite number of times. Meanwhile, the cell exhibits very stable charge/discharge curve with cycling (up to 20 cycles). This is a solid evidence to prove that $\mathrm{Na}_{3} \mathrm{~V}_{2}\left(\mathrm{PO}_{4}\right)_{3} / \mathrm{MoS}_{2}$ soft package sodium-ion full cell using PPDE-CPE shows unprecedented improvements in deformability and internal short-circuit prevention of cells. It is also expected that this monolithic $\mathrm{Na}_{3} \mathrm{~V}_{2}\left(\mathrm{PO}_{4}\right)_{3} /$ $\mathrm{MoS}_{2}$ sodium-ion full cell offers great promise as bendable electrodes in other energy-storage devices, smart electronics, and wearable devices.

On the basis of that, this research will pave the way for designing and exploiting safety-reinforced and wider electrochemical window poly(ethylene glycol) divinyl ether based polymer electrolyte for high-performance sodium ion batteries.

\section{Conclusion}

For the first time, polysulfonamide-supported poly(ethylene glycol) divinyl ether based polymer electrolyte was designed and fabricated toward monolithic sodium ion full battery through in situ polymerization process. As compared to liquid electrolyte, our polymer electrolyte exhibited comprehensive performance in terms of relatively higher ionic conductivity, wider electrochemical window and better flexibility. When evaluated as polymer electrolyte for rechargeable monolithic sodium ion full battery, such polymer electrolyte delivered a reversible capacity as high as $70 \mathrm{mAh} \mathrm{g} \mathrm{g}^{-1}$ even at $10 \mathrm{C}$. In addition, the capacity retention of $84 \%$ over 1000 cycles was achieved for $\mathrm{Na}_{3} \mathrm{~V}_{2}\left(\mathrm{PO}_{4}\right)_{3} / \mathrm{MoS}_{2}$ sodium ion full batteries. To our knowledge, this is the best rate capability and cycling stability of polymer electrolyte for sodium ion full battery. More impressively, such polymer sodium ion full battery demonstrated excellent safety performance and outstanding flexibility even in some harsh condition. We believe this simple and scalable in situ preparation method as well as the promising electrochemical performance of PPDE-SPE will provide new impetus to explore the practical application of polymer electrolyte for monolithic sodium ion full battery. 


\section{Experimental Section}

Sample Collection: Bulk molybdenum disulfide $\left(\mathrm{MoS}_{2}\right)$ was purchased from Alfa Aesar. Sodium vanadium phosphate $\left[\mathrm{Na}_{3} \mathrm{~V}_{2}\left(\mathrm{PO}_{4}\right)_{3}\right]$ was synthesized in our laboratory. Glass fiber (thickness: $200 \mu \mathrm{m})$ was obtained from Whatman Company. Commercialized microporous polypropylene separator was purchased from Celgard Company (USA).

Samples Characterization: A field emission scanning electron microscope (Hitachi S-4800, operating at $3 \mathrm{kV}$ ) was used to observe morphology of the samples. The FTIR spectra of the membranes are obtained using the attenuated total reflection (ATR) attachment on a Frontier FIIR spectrometer (Perkin-Elmer) in the transmission mode from 800 to $4000 \mathrm{~cm}^{-1}$, which is collected with 32 scans and a resolution of $4 \mathrm{~cm}^{-1}$. Thermal shrinkage ratio (TSR) was calculated using the equation (3): $\operatorname{TSR}(\%)=\left[\left(S_{0}-S_{1}\right) / S_{0}\right] \times 100 \%$. $S_{0}$ and $S_{1}$ represent the area of the separator before and after thermal treatment at the varied temperature for $2 \mathrm{~h}$, respectively. The stress-strain curves were measured using an Inston-3300 universal testing machine (USA) at a stretching speed of $1.66 \mathrm{~mm} \mathrm{~s}^{-1}$ with the sample straps of $1 \mathrm{~cm}$ wide and $8 \mathrm{~cm}$ long.

Electrochemical Evaluation: The electrochemical stability of the separator was conducted by a linear sweep voltammetry (LSV). The liquid electrolyte-wetted separator was sandwiched between stainless-steel working electrode and $\mathrm{Na}$ metal reference electrode with $10 \mathrm{mV} \mathrm{s}^{-1}$ scan rate from $0 \mathrm{~V}$ to $5.5 \mathrm{~V}$ versus $\mathrm{Na}^{+} / \mathrm{Na}$. Ionic conductivity of separators was measured by preparing cells were sandwiched between stainless steel blocking electrodes (diameter: $16.2 \mathrm{~mm}$ ). The measurements were performed using Zahner Zennium Electrochemical Workstation over a frequency range from $1 \mathrm{~Hz}$ to $10^{6} \mathrm{~Hz}$ at $25^{\circ} \mathrm{C}$. The ionic conductivity $(\sigma)$ is calculated by employing the equation (4): $\sigma=L / A R_{\mathrm{b}}$, where $L$ is the thickness of the separator sample, $A$ is the contact area between the separator and the electrode, and $R_{\mathrm{b}}$ is the bulk impedance. The cation transference number $\mathrm{t}_{\mathrm{Na}+}$ was evaluated according to the combined complex impedance and DC polarization measurement technique. For this, the samples were sandwiched between a pair of sodium metal electrodes under argon. After having measured the total initial resistance by $A C$ impedance in the frequency ranging from $1 \mathrm{~Hz}$ to $1 \mathrm{MHz}$, a DC potential of $10 \mathrm{mV}$ was applied until a steady state was reached. Finally, the resistance was again measured by $\mathrm{AC}$ impedance. The cationic transference number has been obtained using the equation: (5) $\mathrm{t}_{\mathrm{Na}+}=I_{\mathrm{s}}\left(\Delta V-I_{0} R_{0}\right) / I_{0}\left(\Delta V-I_{\mathrm{s}} R_{\mathrm{s}}\right)$, where $t_{\mathrm{Na}+}$ is the cationic transference number, $\Delta V$ is the potential applied across the cell, $I_{0}$ and $I_{S}$ are the initial and steady-state currents, and $R_{0}$ and $R_{\mathrm{s}}$ are the cell resistances, evaluated using impedance measurements across the cells before and after their $D C$ polarization.

$\mathrm{Na}_{3} \mathrm{~V}_{2}\left(\mathrm{PO}_{4}\right)_{3}$ cathode was prepared by a doctor-blading and the mass ratio of $\mathrm{Na}_{3} \mathrm{~V}_{2}\left(\mathrm{PO}_{4}\right)_{3} /$ Super $\mathrm{P} / \mathrm{LA} 133$ was $8 / 1 / 1(\mathrm{w} / \mathrm{w} / \mathrm{w})$. Rate capability and cycle life of $\mathrm{Na}_{3} \mathrm{~V}_{2}\left(\mathrm{PO}_{4}\right)_{3} / \mathrm{Na}$ half battery tests were carried out using a LAND battery testing system in the voltage range of 2.5-4.0 $\mathrm{V}$ at room temperature. The battery performance was evaluated under a constant charge/discharge current densities form 0.2 to $10 \mathrm{C}$ for rate capability and $1 \mathrm{C}$ for cycle performance test. The coin cell and aluminum soft packaged battery was assembled. $\mathrm{Na}_{3} \mathrm{~V}_{2}\left(\mathrm{PO}_{4}\right)_{3}$ is used as cathode, molybdenum disulfide $\left(\mathrm{MoS}_{2}\right)$ is used as anode, which was prepared by a doctor-blading and the mass ratio of $\mathrm{MoS}_{2} /$ Super P/LA133 was $8 / 1 / 1(\mathrm{w} / \mathrm{w} / \mathrm{w})$.
The initial charge-discharge curves and cycle performance were carried out using LAND battery testing system between 1 and $3.6 \mathrm{~V}$ at different rates. The $\mathrm{C}$-rates in all of the electrochemical measurements are defined based on $1 \mathrm{C}=117 \mathrm{~mA} \mathrm{~g}^{-1}$.

\section{Supporting Information}

Supporting Information is available from the Wiley Online Library or from the author.

\section{Acknowledgements}

This work was financially supported by the Programs of the National Natural Science Foundation of China (Grant No. 21271180), the Strategic Priority Research Program of the Chinese Academy of Sciences (Grant No. XDA09010105), the Qingdao Institute of Bioenergy and Bioprocess Technology Director Innovation Foundation for Young Scientists. Grant No. QIBEBT-DIFYS-201508, Shandong Provincial Natural Science Foundation, China (No. ZR2013FZ001) and "135" Projects Fund of CAS-QIBEBT Director Innovation Foundation.

[1] J. M. Tarascon, M. Armand, Nature 2001, 414, 359.

[2] E. S. Lee, A. Huq, H. Y. Chang, A. Manthiram, Chem. Mater. 2012, 24, 600 .

[3] M. Armand, J. M. Tarascon, Nature 2008, 451, 652.

[4] N. Kamaya, K. Homma, Y. Yamakawa, M. Hirayama, R. Kanno, M. Yonemura, T. Kamiyama, Y. Kato, S. Hama, K. Kawamoto, A. Mitsyi, Nat. Mater. 2011, 10, 682.

[5] H. Li, Z. X. Wang, L. Q. Chen, X. J Huang, Adv. Mater. 2009, 21, 4593.

[6] M. D. Slater, D. Kim, E. Lee, C. S. Johnson, Adv. Funct. Mater. 2013, 23, 947.

[7] V. Palomares, P. Serras, I. Villaluenga, K. B. Hueso, J. Carretero-Gonzalez, T. Rojo, Energy Environ. Sci. 2012, 5, 5884.

[8] L. Wang, Y. H. Lu, J. Liu, M. W. Xu, J. G. Cheng, D. W. Zhang, J. B. Goodenough, Angew. Chem., Int. Ed. 2013, 52, 1964.

[9] X. C. Lu, G. G. Xia, J. P. Lemmon, Z. G. Yang, J. Power Sources 2010, 195, 2431.

[10] S. W. Kim, D. H. Seo, X. H. Ma, G. Ceder, K. Kang, Adv. Energy Mater. 2012, 2, 710.

[11] A. Ponrouch, E. Marchante, M. Courty, J. M. Tarascon, M. R. Palacín, Energy Environ. Sci. 2012, 5, 8572.

[12] H. Pan, Y. S. Hu, L. Chen, Energy Environ. Sci. 2013, 6, 2338.

[13] K. B. Hueso, M. Armand, T. Rojo, Energy Environ. Sci. 2013, 6, 734.

[14] Z. Jian, W. Han, X. Lu, H. Yang, Y. S. Hu, J. Zhou, Z. Zhou, J. Li, W. Chen, D. Chen, L. Chen, Adv. Energy Mater. 2013, 3, 156.

[15] K. Saravanan, C. W. Mason, A. Rudola, K. H. Wong, P. Balaya, Adv. Energy Mater. 2013, 3, 444.

[16] S. Lunell, A. Stashans, L. Ojamaee, H. Lindstroem, A. Hagfeldt, J. Am. Chem. Soc. 1997, 119, 7374.

[17] X. Yu, H. Pan, W. Wan, C. Ma, J. Bai, Q. Meng, S. N. Ehrlich, Y. S. Hu, X. Q. Yang, Nano Lett. 2013, 13, 4721.

[18] Y. Sun, L. Zhao, H. Pan, X. Lu, L. Gu, Y. S. Hu, H. Li, M. Armand, Y. Ikuhara, L. Chen, Nat. Commun. 2013, 4, 1870.

[19] C. Cao, W. Liu, L. Tan, X. Liao, L. Li, Chem. Commun. 2013, 49, 11740.

[20] A. Hayashi, K. Noi, A. Sakuda, M. Tatsumisago, Nat. Commun. 2012, 3, 856. 
[21] X. Huang, J. Solid State Electrochem. 2011, 15, 649.

[22] L. P. Yue, J. J. Zhang, Z. H. Liu, Q. S. Kong, X. H. Zhou, Q. Xu, J. H. Yao, G. L. Cui, J. Electrochem. Soc. 2014, 161, A1032.

[23] C. T. Love, J. Power Sources 2011, 196, 2905.

[24] D. Fu, B. Luan, S. Argue, M. N. Bureau, I. J. Davidson, J. Power Sources 2012, 206, 325.

[25] J. J. Zhang, Z. H. Liu, Q. S. Kong, C. J. Zhang, S. P. Pang, L. P. Yue, X. J. Wang, J. H. Yao, G. L. Cui, ACS Appl. Mater. Interfaces 2013 , $5,128$.

[26] H. E. Park, C. H. Hong, W. Y. Yoon, J. Power Sources 2008, 178, 765.

[27] D. Kumar, S. A. Hashmi, Solid State lonics 2010, 181, 416.

[28] F. Bella, F. Colo, J. R. Nair, C. Gerbaldi, ChemSusChem 2015, 8, 3668.

[29] H. C. Gao, B. K. Guo, J. Song, K. Park, J. B. Goodenough, Adv. Energy Mater. 2015, 5, 1402235.

[30] J. J. Zhang, L. P. Yue, Q. S. Kong, Z. H. Liu, X. H. Zhou, C. J. Zhang, S. P. Pang, X. J. Wang, J. H. Yao, G. L. Cui, J. Electrochem. Soc. 2013, 160, A769.

[31] S. J. Chun, E. S. Choi, E. H. Lee, J. H. Kim, S. Y. Lee, S. Y. Lee, J. Mater. Chem. 2012, 22, 16618.
[32] S. S. Hwang, C. G. Cho, H. Kim, Electrochem. Commun. 2010, 12, 916.

[33] Y. Ding, P. Zhang, Z. Long, Y. Jiang, F. Xu, J. Membr. Sci. 2009, 329, 56.

[34] P. Raghavan, J. Manuel, X. H. Zhao, D. S. Kim, J. H. Ahn, C. Nah, J. Power Sources 2011, 196, 6742.

[35] X. H. Zhou, L. P. Yue, J. J. Zhang, Q. S. Kong, Z. H. Liu, J. H. Yao, G. L. Cui, J. Electrochem. Soc. 2013, 160, A1341.

[36] C. H. Parka, D. W. Kimb, J. Prakashc, Y. K. Suna, Solid State Ionics 2003, 159, 111

[37] S. Komaba, Y. Matsuura, T. Ishikawa, N. Yabuuchi, W. Murata, S. Kuze, Electrochem. Commun. 2012, 21, 65.

[38] Y. Q. Yang, Z. Chang, M. X. Li, X. W. Wang, Y. P. Wu, Solid State Ionics 2015, 269, 1.

[39] Z. L. Jian, W. Z. Han, X. Lu, H. X. Yang, Y. S. Hu, J. Zhou, Z. B. Zhou, J. Q. Li, W. Chen, D. F. Chen, L. Q. Chen, Adv. Energy Mater. 2013, 3, 156 .

[40] K. Chang, W. X. Chen, L. Ma, H. Li, H. Li, F. Huang, Z. Xu, Q. Zhang, J. Y. Lee, J. Mater. Chem. 2011, 21, 6251.

Received: May 5, 2016

Published online: November 3, 2016 